\title{
BMJ Open Factors associated with online victimisation among Malaysian adolescents who use social networking sites: a cross-sectional study
}

\author{
Mary J Marret, ${ }^{1}$ Wan Yuen Choo
}

To cite: Marret MJ, Choo WY. Factors associated with online victimisation among Malaysian adolescents who use social networking sites: a crosssectional study. BMJ Open 2017;7:e014959. doi:10.1136/ bmjopen-2016-014959

- Prepublication history and additional material are available online. To view please visit the journal online (http://dx.doi. org/10.1136/bmjopen-2016014959).

Received 13 November 2016 Revised 21 March 2017 Accepted 25 May 2017

\section{CrossMark}

${ }^{1}$ Department of Paediatrics, Faculty of Medicine, University of Malaya, Kuala Lumpur, Malaysia

${ }^{2}$ Department of Social and Preventive Medicine, Faculty of Medicine, University of Malaya, Kuala Lumpur, Malaysia

Correspondence to Dr Mary J Marret; marret@um. edu.my

\section{ABSTRACT}

Objective To determine the prevalence of online interpersonal victimisation and its association with patterns of social networking site (SNS) use, offline victimisation, offline perpetration and parental conflict among Malaysian adolescents using SNS.

Methods A cross-sectional study of students from randomly selected public secondary schools in the state of Negeri Sembilan was conducted using an anonymous selfadministered questionnaire. The questionnaire examined patterns of SNS use and included measures of online victimisation, online perpetration, offline victimisation and parental conflict. A response rate of $91 \%$ from a total of 1634 yielded a sample of 1487 students between 15 years and 16 years of age.

Results Ninety-two per cent of respondents had used at least one SNS. More than half of SNS users $(52.2 \%)$ reported experiences of online victimisation over the past 12 months. Boys were significantly more likely to experience online harassment compared with girls $(52.2 \%$ vs $43.3 \%, p<0.001)$. There were no significant gender differences in experiences of unwanted sexual solicitation. Adolescents who engaged in perpetration behaviours online had almost six times higher odds of reporting frequent online victimisation compared with online behaviours involving personal disclosure. There was a significant dose-response relationship between engagement in multiple types of online behaviour and the risk of frequent online victimisation. Both online and offline perpetrations were associated with an increased risk of victimisation. Those who were victimised offline or experienced parental conflict were twice as likely to report online victimisation.

Conclusion Interventions to prevent online electronic aggression should target perpetration behaviour both online and offline. Youth should be equipped with skills in communication and decision-making in relationships that can be applied across a spectrum of contexts both online and offline.

\section{INTRODUCTION}

Electronic aggression enacted through a range of behaviour perpetrated via computers, cellphones and other electronic devices has been found to be a common experience among young persons. ${ }^{1-3}$ Prevalence estimates of
Strengths and limitations of this study

Large population-based study

- High response rate

- Examines association of online victimisation with behaviour and experiences both online and offline

- Results are based on self-reporting which is subject to distortions from errors in recollection and social desirability bias

- Cross-section design limits inferences regarding the direction of the associations found

victimisation in the form of harassment range from $5.5 \%$ to $72 \%$. The wide variability in prevalence has been attributed in part to the operational definitions applied, as well as the time frame of assessment. It has been observed that studies using broad definitions and measurement of lifetime experiences have reported higher levels of prevalence. More conservative estimates have emerged from studies with narrow definitions and the limiting of measurements to recent experiences. ${ }^{4-13}$ Varying levels of unwelcomed sexual aggression have been reported across Europe ranging from 1 in 10 (Germany, Iceland, Portugal) to 1 in 2 (Poland). ${ }^{14} \mathrm{~A}$ review of three US surveys reported declining trends from 1 in 5 youth internet users to $9 \%$ over a decade. ${ }^{7}$

The relationship between online interpersonal harassment and aggressive or sexually exploitative offline encounters as well as longer-term mental health outcomes makes this an important public health concern. ${ }^{514-16}$ Exposure to electronic aggression among youth has been associated with emotional disturbances, negative mental health outcomes and a range of internalising and externalising behaviours as well as substance abuse problems. ${ }^{17}$

One of the challenges to research in this field is the absence of consensus on a 
conceptual definition. ${ }^{12}{ }^{18}$ A number of terms with overlapping meanings such as electronic bullying, cyberbullying, cyber-aggression, internet bullying, internet harassment, online harassment or technology-based victimisation have been used to describe this form of violence. ${ }^{12} 1819$ Electronic aggression may be enacted through a range of behaviours. This includes the spreading of harmful lies, directing rude or threatening comments against individuals, spreading of embarrassing rumours and posting of digital photographs or videos intended to humiliate others. These acts may originate from known or anonymous sources. ${ }^{20}$ The term 'cyberbullying' is usually applied to online aggression perpetrated by peers that overlaps with traditional bullying. ${ }^{21}$ The term 'online harassment' encompasses a broader range of offences, committed by known or anonymous sources of any age, which occur in a setting outside adult supervision and scrutiny. ${ }^{21}$ Electronic aggression of a sexual nature directed towards an unwilling subject has been termed 'unwanted sexual solicitation'. This can take the form of invitations to talk about sex, do something sexual or share personal sexual information that may be diverse in nature and origin. ${ }^{22}$ Perpetrators of this type of behaviour are usually male. ${ }^{23}$ Such acts may originate from troubled youth with a history of other behavioural problems or adult sexual predators engaged in deliberate manipulation and seduction of minors. ${ }^{22} 2425$ The latter are not limited to strangers encountered online. They may include adults within the family and social circle. ${ }^{25}$ Distinctive characteristics of electronic aggression include greater permanence of content, visibility to a wider audience and repeat victimisation without active involvement of the perpetrator. ${ }^{26-28}$ The possibility of attacking remotely at any time of the day or night with multiple media makes the victimisation experience more intrusive and difficult to escape. ${ }^{3} 29$ Anonymity and blinding of perpetrators to their victim's reactions may reduce inhibitions, foster deindividuation, reduce accountability and promote antinormative behaviours. $^{20}$

With its diversity in form, expression, participants and underlying motivations, no robust theoretical model has been identified which can adequately explain the phenomenon of electronic aggression. ${ }^{30}$ A number of contextual factors associated with its occurrence among youth have been studied to identify opportunities for intervention and prevention. They include demographic characteristics of victims, patterns of internet use, online behaviour and experiences of offline victimisation.

From a developmental perspective, the amount of time spent online as well as the degree of social interaction online may vary with age. Forms and expressions of aggression may also evolve with changing levels of maturity. These differences may play a part in the level of online victimisation experienced by different age groups. ${ }^{30} \mathrm{An}$ increasing trend of cyberbullying between the ages of 11 years and 15 years that peaks in middle school and subsequently declines in high school has been reported. ${ }^{131-33}$
However not all studies have found a consistent relationship between cyberbullying and age. ${ }^{8}$

Examination of online victimisation in relation to gender has yielded a mixed picture. A preponderance of female victimisation has been reported in some studies from North America and Europe. ${ }^{2} 141732$ 34-37 This may reflect targeting of victims based on gender. This could also be due to the involvement of more girls in indirect bullying, as both bullies and victims. ${ }^{130}$ Data from the UK Children Go Online (UKCGO) and Safety Awareness Facts and Tools Surveys conducted in Europe found variations across countries and age groups. Higher levels of victimisation were found among older teenage girls in UK and Norway, and among boys aged 9 years to 12 years in Ireland. ${ }^{9} \mathrm{~A}$ few studies have not found gender-based victimisation patterns. ${ }^{31} 38$ Others, mainly from Asia, have reported a preponderance of boys in combined roles of perpetrators and victims. ${ }^{11} 1540$ One of these studies from Mainland China attributed this gender difference to patterns of upbringing. In traditional Chinese culture, girls are expected to be gentle, kind and polite whereas boys are encouraged to be more assertive. ${ }^{11}$

Patterns of internet use have been explored in relation to the routine activities theory ${ }^{41}$ which predicts higher levels of victimisation among those with greater exposure to risk through their activities. ${ }^{42}$ Support for this theory has been found in the association of online interpersonal victimisation with increased time spent online ${ }^{822}$ and increased digital competence. $^{14}$

With regard to online behaviour, disclosure of personal information to online acquaintances ${ }^{154344}$ and harassing others online ${ }^{22}{ }^{44}$ have been found to be associated with increased risks of online interpersonal victimisation. Cumulative engagement in multiple activities individually identified as risky has been associated with escalation of the risk of online interpersonal victimisation. ${ }^{44}$ There is also evidence linking engagement in risky online behaviour and online interpersonal victimisation with offline experiences and behaviour. These include victimisation in the form of child abuse and bullying, engagement in offline physical relational and sexual aggression as well as conflicts with caregivers. ${ }^{10} 1621224546$ These offline experiences have existed prior to the advent of new communication technologies. It has been postulated that the integration of the internet into the lives of youth has resulted in the extension of problems encountered offline to online interactions. Consequently, a broad view which incorporates electronic victimisation within the victimisation spectrum has been proposed by some researchers in preference to considering traditional and electronic victimisation as separate entities. ${ }^{13} 47$ This perspective would be valuable in seeking strategies to reduce the prevalence of various forms of youth victimisation as a whole. ${ }^{13}$ Current research suggests that the determinants of exposure to online interpersonal victimisation and consequent harm are a composite of general factors that may interact with specific factors which enhance individual vulnerability. General factors include 
adolescent-related interests in social communication and sexual exploration, gender, as well as cultural norms. ${ }^{48} 49$ Specific vulnerabilities may be related to past or concurrent offline victimisation, difficult family relationships, alternative sexual orientation, problem behaviour, substance abuse and accompanying psychosocial difficulties which could influence the propensity to engage in problematic interactions online. ${ }^{164349}$

The objective of this study was to determine the prevalence of online interpersonal victimisation among Malaysian adolescents using social networking sites (SNS) and its association with patterns of SNS use, offline victimisation, offline perpetration as well as parental conflict. There is a lack of research to explore risks encountered by youth using digital communication from middle-income Asian countries such as Malaysia. Over the past decade, there has been rapid expansion in the internet penetration rate and the use of mobile communication devices throughout Malaysia. A programme called CyberSAFE (cybersecurity and awarness for everyone) in schools was launched by the Malaysian government in response to emerging safety threats. ${ }^{50}$ Through a partnership between government agencies and the telecommunication industry, a series of training workshops on cybersecurity have been conducted for teachers and students across the country. ${ }^{51}{ }^{52}$ Concomitant school surveys within this programme have found that electronic aggression is a common problem, especially among older adolescents. ${ }^{50}$ Almost half of those surveyed were found to practise low levels of online safety. Another finding was that awareness of online dangers did not translate into positive action. ${ }^{51}$ Building on these preliminary findings, this study explores factors which may contribute to victimisation. This would provide an evidence base for designing interventions to reduce online victimisation. The study findings would also be relevant in the formulation of policies and legislation to protect young persons.

SNS incorporate features which facilitate communication and the development of social relationships. These include (1) the integration of various levels of private and public communication (2) accessibility to a network of contacts (3) the ability to display and exchange personal information in textual form as well as digital images. ${ }^{53}$ However the same features simultaneously generate avenues for victimisation. ${ }^{14} 4255$ The SNS platform was selected to study electronic aggression among youth based on these features and its popularity among adolescents as a communication tool. ${ }^{50535456}$

Based on the aforementioned research, factors which could affect exposure to online interpersonal victimisation were organised into a conceptual framework (figure 1). The focus of this study was on variables associated with greater intensity of victimisation as measured by frequency.

Older adolescents were selected for this study. This age group was identified to be vulnerable by the Malaysian CyberSAFE programme. ${ }^{50} 51$

The following research questions were addressed:

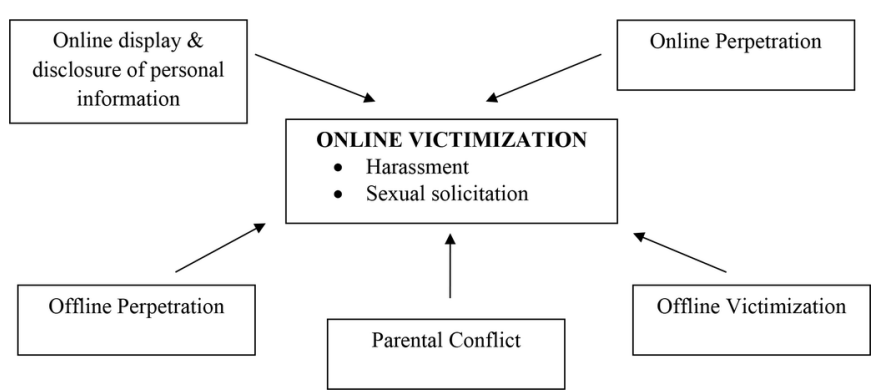

Figure 1 Conceptual framework of factors which may affect exposure to online victimisation.

1. What is the prevalence of SNS usage and specific online behaviours among adolescents?

2. What is the prevalence of online or offline victimisation and perpetration experienced by adolescents using SNS?

3. Is there an association between frequent online victimisation and online behaviour?

4. Is there an association between frequent online victimisation and experiences of offline victimisation, online perpetration, offline perpetration and parental conflict?

\section{METHODS}

\section{Sample}

The study was conducted with students from public secondary schools in the state of Negeri Sembilan. The multiethnic composition within this state resembles that of the national population. Twelve schools ( 7 urban, 5 rural) were randomly selected from a list of 117 schools. The sample was drawn from Form 4 students between 15 years and 16 years of age. For each selected school, four to five classes of Form 4 students were randomly selected. Sample size was calculated based on previous studies of online victimisation reporting prevalence rates ranging from $5 \%$ to $55 \% .{ }^{922} 57$ An upper estimate that $55 \%$ of students would be likely to experience at least one type of victimisation was used. We assumed a CI of $95 \%$ and precision of $2.5 \%$, inflated for missing data of $30 \%$. These assumptions yielded a sample size of approximately 1560 .

\section{Procedure}

Students completed an anonymous self-administered paper and pencil questionnaire. Participation was voluntary with assurances that confidentiality would be maintained and responses would not influence school grades. The surveys were conducted in classes in a single session. Questionnaires were administered without the presence of class teachers. These procedures were necessary to increase response and disclosure. At the end of every survey session, all students were provided with an information sheet containing a list of contacts of available support services and helplines. 


\section{Instrument}

Details of the questionnaire are provided in supplementary material 1 . The questionnaire contained items regarding sociodemographic characteristics and details regarding the use of SNS. A number of items measured risky online behaviour relating to the public display of personal information, interaction with individuals encountered online without a prior offline introduction and disclosure of personal information to such individuals. Online victimisation as well as online perpetration in the form of harassment and unwanted sexual solicitation in the previous 12 months was measured with questions adapted from the Growing Up with Media Survey and the Youth Internet Safety Survey. ${ }^{22} 44$ Lifetime experiences of offline victimisation were assessed using the validated International Society for the Prevention of Child Abuse and Neglect (ISPCAN) Child Abuse Screening tool for young adults. ${ }^{58}$ Offline perpetration was measured in three domains (psychological, physical, sexual) with four stem questions from the Growing Up with Media Survey. ${ }^{22}$ A validated version of the Measure of Parenting Style was used to assess parental conflict levels. ${ }^{59}$

\section{Statistical analysis}

Data were analysed using Statistical Package for Social Sciences (SPSS) windows V.22.0. Descriptive statistics of the type and frequency of specific risky online behaviours, victimisation and perpetration experiences were reported in proportions. Subgroup analysis focusing on gender differences of these behaviours and experiences were also examined and reported. Missing data for each variable of interest were less than $5 \%$ of the cases, and listwise deletion analysis was conducted for complete cases. Multiple logistic regression analysis was used to estimate the odds of reporting frequent online victimisation among SNS users. The odds of frequent online victimisation were estimated for specific online behaviour, types of online behaviour and engagement in multiple forms of online behaviour. The odds were adjusted for demographic and SNS use characteristics. Next, ORs were estimated to examine the association between offline victimisation, parental conflict as well as online perpetration with frequent online victimisation by further adjusting for the total number of online behaviours.

\section{RESULTS}

\section{Sociodemographic characteristics}

The response rate from a total of 1634 students was 91\% after eliminating 3 refusals and 144 incomplete responses. The 1487 respondents were aged between 15 years to 16 years of age, of which $53.9 \%$ were female. They comprised predominantly Malay $(69.6 \%)$ followed by $16.7 \%$ Indian, $13.6 \%$ Chinese and $0.2 \%$ other ethnic groups. Approximately $90 \%$ were living with both of their parents. Seventy per cent of their parents had completed at least a secondary school education. As there were no significant differences between data from urban and

\begin{tabular}{|c|c|c|c|c|}
\hline $\begin{array}{l}\text { Specific online } \\
\text { behaviour }\end{array}$ & $\begin{array}{l}\text { Male } \\
(n=646) \\
(\%)\end{array}$ & $\begin{array}{l}\text { Female } \\
(n=718) \\
(\%)\end{array}$ & $\begin{array}{l}\text { Total } \\
(n=1364) \\
(\%)\end{array}$ & $p$ value \\
\hline $\begin{array}{l}\text { Posting personal } \\
\text { information on a } \\
\text { public profile }\end{array}$ & 36.1 & 29.7 & 32.7 & 0.012 \\
\hline $\begin{array}{l}\text { Sending personal } \\
\text { information to a } \\
\text { stranger }^{\star}\end{array}$ & 45.2 & 47.5 & 46.4 & 0.397 \\
\hline $\begin{array}{l}\text { Posting revealing } \\
\text { photographs or } \\
\text { videos }\end{array}$ & 2.2 & 0.8 & 1.5 & $<0.001$ \\
\hline $\begin{array}{l}\text { Interaction with } \\
\text { stranger }\end{array}$ & 89.9 & 86.5 & 88.1 & 0.050 \\
\hline $\begin{array}{l}\text { Perpetration of } \\
\text { harassment }\end{array}$ & 37.2 & 27 & 31.8 & $<0.001$ \\
\hline $\begin{array}{l}\text { Perpetration of } \\
\text { unwanted sexual } \\
\text { solicitation }\end{array}$ & 5.3 & 0.4 & 2.7 & $<0.001$ \\
\hline
\end{tabular}

$p$ value based on Pearson's $\chi^{2}$ test comparing differences in risky online behaviours between genders.

$p$ value in bold significant at $p<0.05$.

*'stranger' refers to a contact encountered solely through an online SNS without a prior face-to-face meeting.

rural schools, results from both groups of schools were merged and analysed together.

\section{Prevalence of SNS usage}

Ninety-two per cent of respondents had used at least one SNS. The rest of the analysis was based on this subset denoted as 'SNS users'. More than a third of SNS users started at the age of 12 years or younger, below the recommended age for SNS use. The most commonly used SNS was Facebook. Approximately half of the adolescents possessed more than one profile and $45.4 \%$ accessed their profiles daily. Duration of weekly use ranged from $20 \mathrm{~min}$ to 100 hours with a median of 3 hours. Two-thirds had more than 300 'friends' or contacts in their profile, with a third reporting more than a 1000 contacts. Communication and social interaction were found to be the most important reasons for SNS use compared with other purposes such as leisure, keeping up with peers and public participation. Half of the respondents (50.2\%) acknowledged using SNS to meet new people and make new friends. Three quarters $(74.5 \%)$ had accepted requests to include unknown persons into the list of contacts with no significant gender differences.

\section{Prevalence of specific risky online behaviour}

The prevalence of different types of online behaviours involving personal information disclosure, interaction with strangers and online perpetration is shown in table 1. Of these, the most commonly reported online behaviour was interacting with strangers while the posting of revealing images was the least common. 


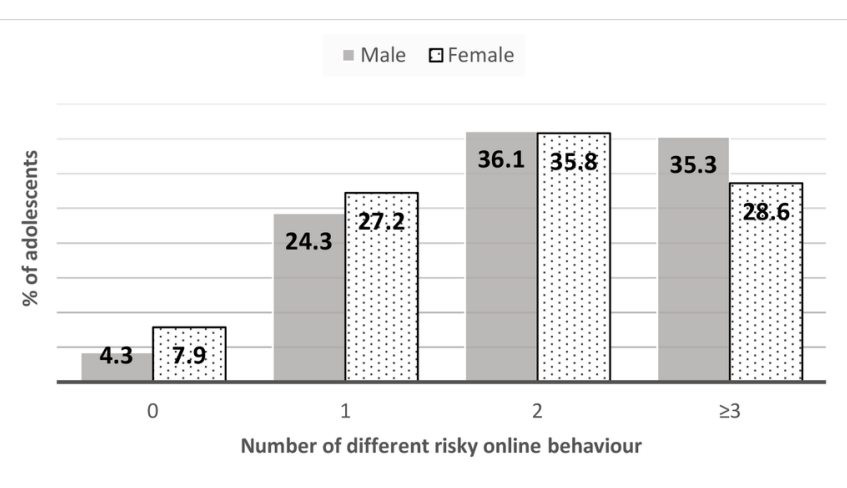

Figure 2 Cumulative risky online behaviour by gender.

With the exception of sending personal information to strangers, most of the listed behaviours including online perpetration were found to be more common among boys. Approximately one in three had engaged in at least one of the six listed behaviours while nearly a third had engaged in three or more $(31.8 \%)$. There was a significant upward trend of engagement in multiple risky online behaviours among boys compared with girls $(p<0.001)$ (see figure 2).

\section{Prevalence of Victimisation}

The prevalence of online victimisation, online perpetration, offline victimisation and offline perpetration by gender is shown in table 2.

\section{Online victimisation}

More than half of the respondents $(52.2 \%)$ had experienced some form of online victimisation. The prevalence of online harassment was higher than unwanted sexual solicitation. Boys were significantly more likely to experience online harassment compared with girls. While girls were more likely to report unwanted sexual solicitation, the gender difference was not statistically significant. Frequent online victimisation was slightly more common among boys than girls.

\section{Online perpetration}

One in three respondents reported engaging in some form of perpetration online. Perpetration of online harassment or aggression was more common than unwanted sexual solicitation. Boys had a significantly higher prevalence of both types of behaviour and were more likely to be frequent perpetrators.

\section{Offline victimisation}

There was a high prevalence of offline victimisation in general $(60.3 \%)$ reported by the study population with about a third of SNS users reporting experiences of multiple types of victimisation. Physical victimisation was the most prevalent, followed by psychological and sexual. There were no significant gender differences found among subtypes of victimisation except for psychological victimisation which was more prevalent among girls.

\section{Offline perpetration}

Offline perpetration was reported by $37.5 \%$ of the respondents. About a quarter of the respondents reported having perpetrated either psychological or physical aggression towards others. The prevalence of offline sexual perpetration was much lower, at around 3\%, and was more commonly reported by boys. About 1 in every 10 respondents had engaged in multiple types of perpetration.

\section{Association between risky online behaviour and online victimisation}

The association between frequent online victimisation and online behaviour is summarised in table 3. Results were adjusted for sociodemographic and SNS use characteristics. The posting of revealing photographs was the only behaviour involving personal disclosure which was associated with a higher risk of online victimisation. Adolescents who engaged in perpetration behaviours were six times more likely to report frequent online victimisation, compared with online behaviours involving personal disclosure. There was a significant dose-response relationship between engagement in multiple types of online behaviour and the risk of frequent online victimisation. Neither the length of time spent on SNS nor the number of people in the respondents' contact lists were found to be associated with frequent online victimisation.

\section{Correlates of frequent online victimisation}

Both online and offline perpetration were found to be associated with an increased risk of online victimisation when adjusted for sociodemographic and internet use characteristics. The observed relationship remained strongly significant after adjustment for total number of online behaviours (see table 4). Specifically, adolescents who engaged in frequent online perpetration were 12 times more likely to report frequent online victimisation. Similarly, an upward trend of frequent online victimisation was seen among those who engaged in multiple types of perpetration.

While adolescents who were victimised in the offline world were twice more likely to report online victimisation, the odds did not increase with exposure to multiple types of offline victimisation. Respondents who experienced high levels of parental conflict were twice more likely to be harassed or victimised online.

\section{DISCUSSION}

The high prevalence of SNS users and reported motivation for use are consistent with studies in Europe and other local studies. ${ }^{54566061}$ Initiation of SNS use at a young age mirrors findings in Europe where 27\% of children aged 9-10years said they had an SNS profile. ${ }^{62}$ Knowledge of these demographic patterns should be applied in initiatives to address the overall safety, well-being and development of youth. ${ }^{63}$

Higher levels of interaction with unknown persons were found than what has been previously reported in the $\mathrm{USA}^{64}$ or locally. ${ }^{57}$ This may be due to adolescents 
Open Access

Table 2 Prevalence of victimisation and perpetration experiences by types and gender

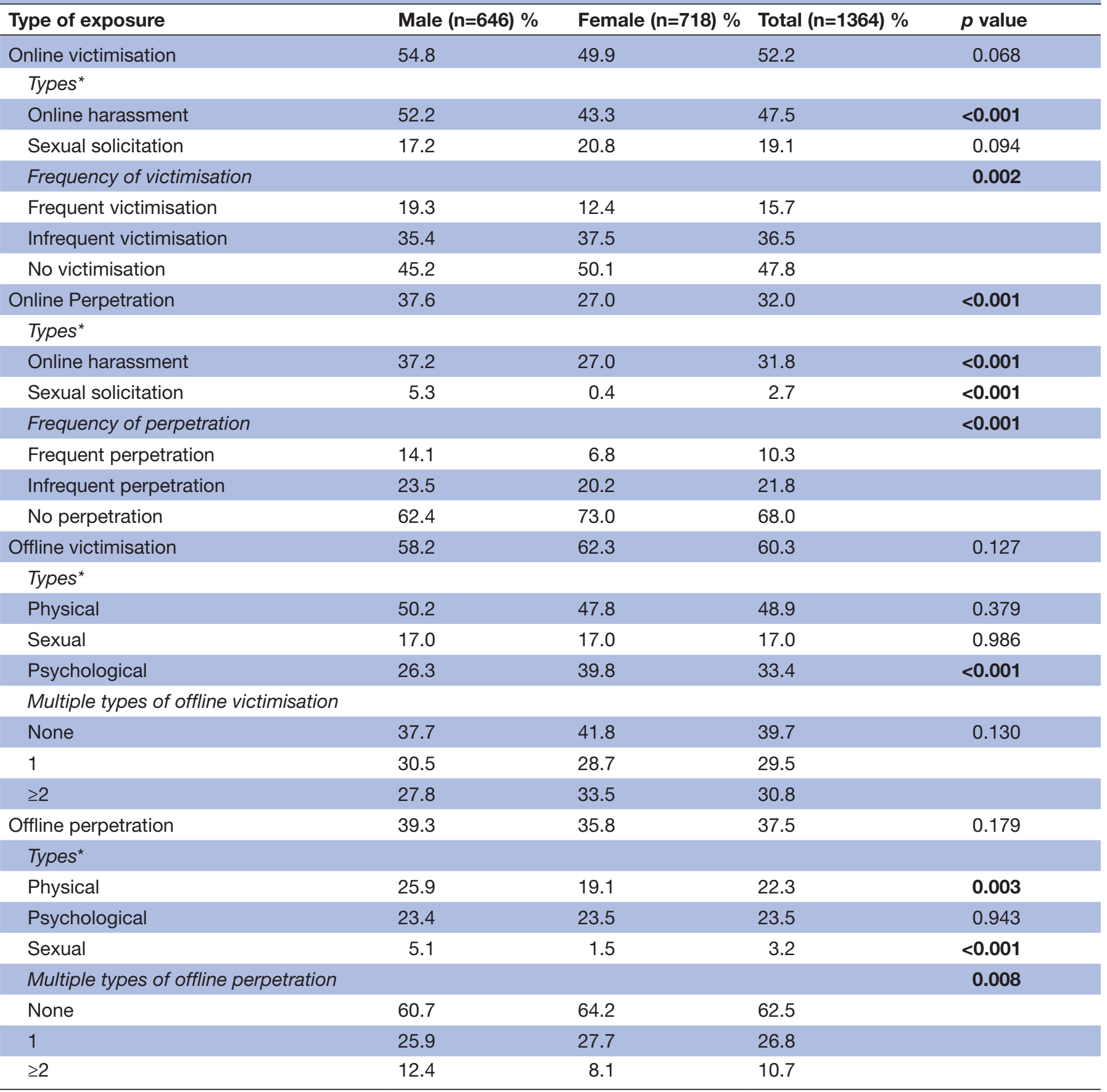

$p$ value based on Pearson's $\chi^{2}$ test comparing victimisation or perpetration experiences by gender. Bold text indicates statistically significant $p$ values.

${ }^{*}$ Categories are not mutually exclusive.

maximising avenues for social communication and sexual exploration away from adult scrutiny, particularly within the context of a conservative Asian and predominantly Muslim community. It could also be the consequence of boredom, curiosity and social inhibitions in face-to-face encounters. ${ }^{65}$ When such behaviour is normative, a communication-based approach to education on safeguarding individual privacy and security is more likely to be effective than a restrictive approach. $^{66}$

The prevalence of online harassment in this study falls within the wide range of existing prevalence estimates of $5.5 \%$ and $72 \%,{ }^{4-11}$ confirming that the problem extends to youth in this region and needs to be addressed. The odds of experiencing harassment are marginally higher among youth who report online interaction with strangers suggesting that harassment originates predominantly 
Table 3 Association of online victimisation with risky online behaviours

Odds of online victimisation

Adjusted for sociodemographic Adjusted for SNS use characteristics

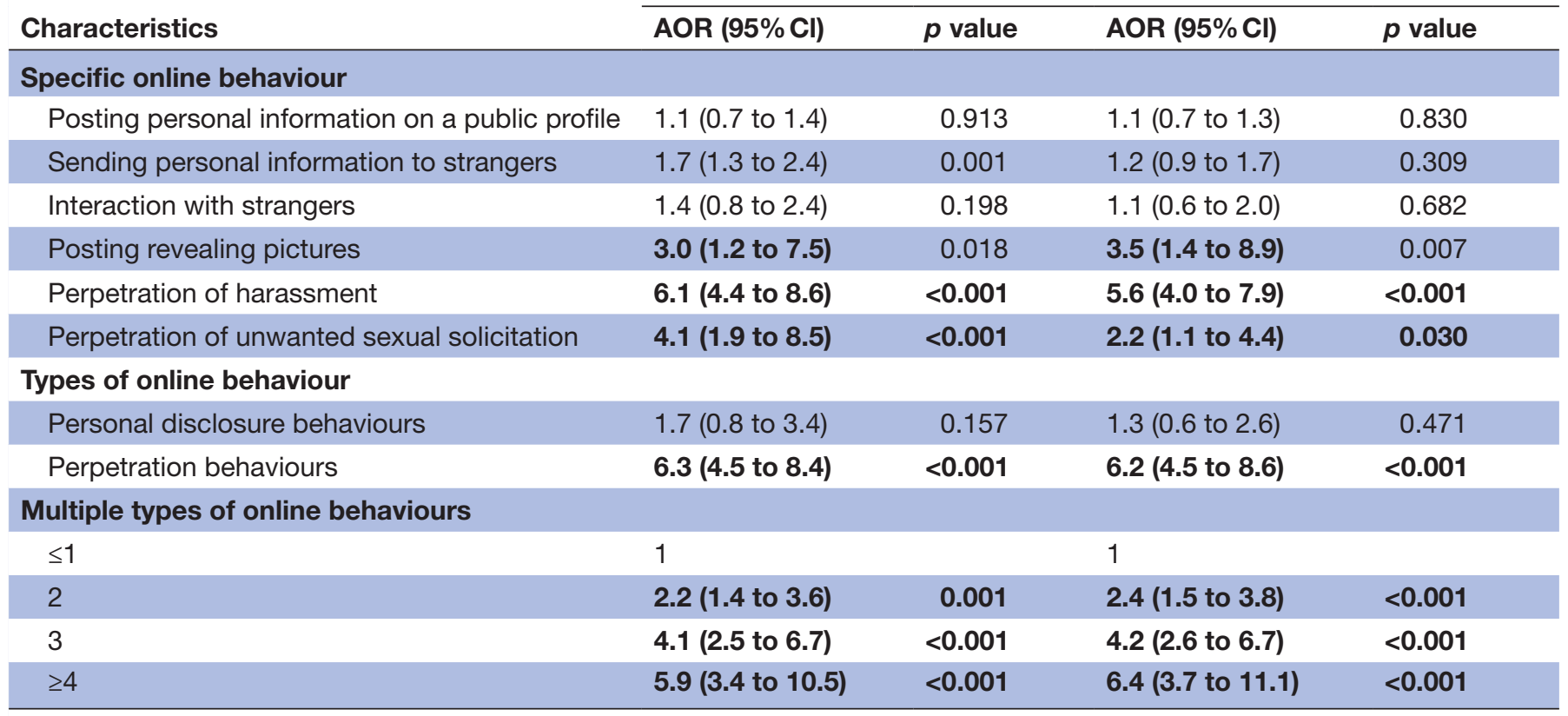

Personal disclosure behaviours consist of posting and sending personal information, interacting with strangers and posting revealing pictures. Perpetration behaviours include adolescents perpetrating harassment and unwanted sexual solicitation.

ORs are adjusted for (1) sociodemographic characteristics (ethnicity, gender, geographic location, parent's relationship status and parent's education level) and (2) SNS use (frequency and age of SNS access).

Bold text indicates statistically significant $\mathrm{p}$ values.

AOR, adjusted OR.

from known persons. This may include peers who concurrently bully them offline as has been reported by others. ${ }^{114567}$ This could not be verified within this study design as there was no specific enquiry to determine if respondents were harassed online and offline by the same individuals. The higher prevalence of online harassment compared with unwanted sexual solicitation resembles the pattern of offline victimisation found in this study and other studies, where levels of physical and psychological victimisation exceed sexual victimisation. ${ }^{68} 69$

The higher levels of online harassment experienced by boys in this study has also been reported in other Asian studies. ${ }^{11} 15$ This is likely to be related to gender differences in online behaviour. In this study, the most important predictors of frequent online victimisation were online perpetration of harassment and unwanted sexual solicitation followed by the posting of revealing pictures (table 3). These behaviours were more prevalent in boys, who also had a significantly higher prevalence of engagement in multiple risky online behaviours (figure 2). While a number of studies have found increased electronic aggression directed at girls and a few others reported no gender differences, these have been conducted in Western populations. ${ }^{2} 14313234-38$ We postulate that cultural conditioning and expectations may partly account for these differences. ${ }^{11}$ In Asian communities including Malaysia, there is greater tolerance for aggressive behaviour in boys, who are encouraged to be assertive. In contrast, rude or aggressive behaviour, initiating sexual conversations or sharing of revealing photographs by girls evokes criticism, even from peers. This may inhibit their online behaviour and lower their risk of online victimisation. These differences suggest that victimisation patterns may vary across cultures. This reinforces the value of conducting local research to determine the applicability of international data to specific settings.

The prevalence of unwanted sexual solicitation in this study is higher than recent US studies whereas research from Europe has revealed a wide variation. ${ }^{79}$ The steady decline in the USA has been attributed to increased consciousness with the introduction of internet safety education programmes as well as changing patterns of use and better law enforcement. In comparison, safety education programmes are in early stages of development in Malaysia. In contrast to other studies, the absence of gender differences in this study is consistent with previous Malaysian studies on offline victimisation. ${ }^{70} 71$ This could be related to greater involvement of boys with online perpetration and risky behaviour such as posting of revealing images on their SNS profile. With the widespread utilisation of SNS by the majority of youth for an ever-growing range of functions related to leisure activities and social communication, it is postulated that the 
Table 4 Association between online victimisation with offline and online correlates

Odds of online victimisation

\begin{tabular}{|c|c|c|c|c|}
\hline \multirow[b]{3}{*}{ Characteristics } & \multicolumn{2}{|c|}{ Model 1} & \multicolumn{2}{|c|}{ Model 2} \\
\hline & \multicolumn{2}{|c|}{$\begin{array}{c}\text { Adjusted for sociodemographic and SNS use } \\
\text { characteristics }\end{array}$} & \multicolumn{2}{|c|}{ Adjusted for total no. of online behaviours } \\
\hline & AOR $(95 \% \mathrm{Cl})$ & $p$ value & AOR $(95 \% \mathrm{Cl})$ & $p$ value \\
\hline \multicolumn{5}{|l|}{ Online perpetration } \\
\hline None & 1 & NA & 1 & NA \\
\hline Infrequent & $2.6(1.8$ to 4.0$)$ & $<0.001$ & $1.8(1.5$ to 2.0$)$ & $<0.001$ \\
\hline Frequent & 21.8 (13.8 to 34.5 ) & $<0.001$ & 12.5 (8.2 to 18.9$)$ & $<0.001$ \\
\hline \multicolumn{5}{|l|}{ Offline perpetration } \\
\hline None & 1 & NA & 1 & NA \\
\hline Offline perpetration & 2.0 (1.5 to 2.8 ) & $<0.001$ & 1.6 (1.2 to 2.2$)$ & $<0.001$ \\
\hline \multicolumn{5}{|l|}{$\begin{array}{l}\text { Multiple types of } \\
\text { offline perpetration }\end{array}$} \\
\hline 0 & 1 & NA & 1 & NA \\
\hline 1 & 1.6 (1.1 to 2.3$)$ & 0.013 & 1.3 (0.9 to 1.8 ) & 0.171 \\
\hline 2 & 2.9 (1.8 to 4.7$)$ & $<0.001$ & 2.4 (1.5 to 3.7 ) & $<0.001$ \\
\hline 3 & 12.3 (3.0 to 50.2 ) & $<0.001$ & 7.9 (2.3 to 27.2$)$ & 0.001 \\
\hline \multicolumn{5}{|l|}{ Offline victimisation } \\
\hline None & 1 & NA & 1 & NA \\
\hline Offline victimisation & 1.8 (1.3 to 2.6 ) & $<0.001$ & 1.7 (1.2 to 2.3 ) & 0.001 \\
\hline \multicolumn{5}{|l|}{$\begin{array}{l}\text { Multiple types of } \\
\text { offline victimisation }\end{array}$} \\
\hline 0 & 1 & NA & 1 & NA \\
\hline 1 & $1.4(0.9$ to 2.1$)$ & 0.136 & $1.0(0.7$ to 1.6$)$ & 0.654 \\
\hline 2 & $2.2(1.4$ to 3.4$)$ & $<0.001$ & $1.4(0.9$ to 2.1$)$ & 0.117 \\
\hline 3 & 3.1 (1.8 to 5.5$)$ & $<0.001$ & 1.6 (0.9 to 2.7$)$ & 0.075 \\
\hline \multicolumn{5}{|l|}{ Parental conflict } \\
\hline Low & 1 & NA & 1 & NA \\
\hline Medium & 1.5 (0.9 to 2.3$)$ & 0.067 & $1.6(1.5$ to 1.9$)$ & $<0.001$ \\
\hline High & 2.2 (1.5 to 3.2 ) & $<0.001$ & 1.7 (1.2 to 2.51$)$ & 0.003 \\
\hline
\end{tabular}

Model 1: ORs were adjusted for sociodemographic (ethnicity, gender, geographical location, parent's relationship status and parent's education level) and SNS use characteristics (frequency of access and age of first access).

Model 2: ORs were adjusted for total number of online behaviours (posting personal information on a public profile, posting revealing photographs or videos, sending personal information to strangers, interacting with strangers, perpetration of harassment and unwanted sexual solicitation), besides demographic and SNS use characteristics.

AOR, adjusted OR; NA, data not applicable.

time spent online may not be a discriminator of victimisation risk, unlike earlier studies. ${ }^{21}$ This may explain why the duration of time spent online was not a predictor of victimisation in this study.

Personal information disclosure other than the posting of revealing images was associated with a marginal increase in the odds of online victimisation. Marked risk escalation occurred only when this was combined with a number of other behaviours. This extends the evidence found in another USA-based study where engagement in four types of online behaviour was associated with a steep rise in the risk of online interpersonal victimisation. $^{44}$ Among component behaviours, uploading personal revealing photographs and online perpetration were major contributors to risk of online victimisation in this study. Involvement in four or more listed types of behaviour was seen in less than $10 \%$ of respondents in this study. Participation in multiple types of risky behaviour may be a possible marker of individuals with a greater willingness to forgo privacy for self-disclosure as well as to provoke others. ${ }^{2426672}$ Instead of targeting individual types of behaviour in isolation, understanding the psyche of adolescents who belong to this high-risk group may yield more useful strategies for prevention and suggest directions for future research. 
Demonstration of the association of frequent online victimisation with offline victimisation experiences and parental conflict underlines the importance of taking into account broader contextual factors in formulating an understanding of contributors to the risk of online victimisation. The adverse psychosocial impact of previous victimisation may result in emotional dysregulation and lack of social competence. Convergence of psychosocial difficulties with family conflict and weak family ties may increase an individual's risk of becoming a target of victimisation in different ways. Affected persons may be drawn into intimate interactions online, exercise less discretion in their uploading of content and have an increased propensity to express hostility in their online exchanges. ${ }^{162243}$

The study findings that both online and offline perpetration are important predictors of online victimisation adds to evidence from previous studies. ${ }^{43}$ Examining underlying motivations and triggers of this form of aggression would be a logical step to address online victimisation. As adolescents seek to establish their identity and grapple with issues relating to intimacy and sexuality, ${ }^{48}$ aggression may be employed as a strategy offline and online to establish and maintain social dominance. This could result in subsequent targeting for victimisation by rivals. ${ }^{73}$

The following study limitations are acknowledged. Results are based on self-reporting which is subject to distortion from errors in recollection and social-desirability biases that could result in under-reporting. ${ }^{48}$ The high response rate and the anonymity assured in the study increased the possibility of reporting an unwanted experience among the adolescents. The cross-sectional design limits inferences regarding the direction of associations found. The relationship between perpetration and victimisation may be bidirectional, that is, perpetration could result in victimisation or be a reaction to victimisation, extending across online and offline interactions. In addition, other factors such as academic performance, ${ }^{15} 37$ sexual orientation ${ }^{74}$ and conduct problems, ${ }^{22}{ }^{45}$ which have been found to be associated with online victimisation, were not explored in this study. The narrow age range and predominantly Malay respondents in this sample limits generalisability. Further studies across a wider age group could be a direction for future research.

\section{CONCLUSION}

More than half of Malaysian youth SNS users have encountered victimisation both online and offline. Approximately a third have engaged in perpetration online and offline. Boys experienced more frequent online harassment compared with girls. However there were no significant gender differences in experiences of unwanted sexual solicitation online. Engagement in online perpetration and multiple types of online risky behaviour was more prevalent in boys and associated with higher odds of frequent online victimisation. Experiences of offline victimisation, parental conflict and engagement in perpetration offline were also associated with higher odds of frequent online victimisation.

The study establishes that perpetration behaviour both online and offline should be an important target for intervention to prevent online electronic aggression, with a particular focus on boys. It also demonstrates the need to equip both genders with coping strategies to deal with unwanted sexual solicitation. ${ }^{43}$ While specific affordances within platforms may facilitate victimisation and evolve with development of new technologies, the focus should be on equipping youth with skills in communication and decision-making in relationships that can be applied across a spectrum of contexts both online and offline. ${ }^{63}$ The findings of a high prevalence of offline victimisation and its association with online victimisation suggest that prevention efforts should be directed across a broad spectrum of victimisation types instead of diverting resources to focus on online victimisation. ${ }^{13}$ In addition, adolescent healthcare professionals should be aware of the need to explore other forms of victimisation in adolescents who disclose online victimisation. ${ }^{68}$

Acknowledgements The authors thank the Malaysian Ministry of Education and various schools for study approval, the University of Malaya for administrative support, and Ms Mogana Subramani for assistance with data collection. The authors also thank the students for their willingness to participate in this study.

Contributors MJM conceived the study design, supervised the data collection and wrote the manuscript. WYC carried out the statistical analysis and co-wrote the manuscript.

Funding University of Malaya grants (UMRG 392//11HTM and GC001B-14HTM). Competing interests None declared.

Patient consent Parental/guardian consent obtained.

Ethics approval Institutional approval was granted by the Medical Ethics Committee of the University of Malaya Medical Centre (MEC890.97). Permission for data collection was obtained from the Ministry of Education of Malaysia and the state Department of Education of Negri Sembilan. Informed consent was obtained from school authorities and parents. Students gave their assent to participation

Provenance and peer review Not commissioned; externally peer reviewed.

Data sharing statement The Ministry of Education of Malaysia does not permit sharing of the dataset to maintain privacy.

Open Access This is an 0pen Access article distributed in accordance with the Creative Commons Attribution Non Commercial (CC BY-NC 4.0) license, which permits others to distribute, remix, adapt, build upon this work non-commercially, and license their derivative works on different terms, provided the original work is properly cited and the use is non-commercial. See: http://creativecommons.org/ licenses/by-nc/4.0/

(c) Article author(s) (or their employer(s) unless otherwise stated in the text of the article) 2017. All rights reserved. No commercial use is permitted unless otherwise expressly granted.

\section{REFERENCES}

1. Kowalski RM, Limber SP. Electronic bullying among middle school students. J Adolesc Health 2007;41:S22-S30.

2. Lenhart A, Madden M, Smith A, et al. Teens, kindness and cruelty on social network sites. Washington DC: Pew Research Center, 2011.

3. Tokunaga RS. Following you home from school: a critical review and synthesis of research on cyberbullying victimization. Comput Human Behav 2010;26:277-87.

4. Arslan S, Savaser S, Hallett V, et al. Cyberbullying among primary school students in Turkey: self-reported prevalence and associations with home and school life. Cyberpsychol Behav Soc Netw 2012;15:527-33. 
5. Finkelhor D, Mitchell K, Wolak J. Online victimization: A report on the nation's youth. Virginia: National Center for Missing and Exploited Children, 2000.

6. Hinduja S, Patchin JW. Social influences on cyberbullying behaviors among middle and high school students. $J$ Youth Adolesc 2013;42:711-22.

7. Jones LM, Mitchell KJ, Finkelhor D. Trends in youth internet victimization: findings from three youth internet safety surveys 20002010. J Adolesc Health 2012;50:179-86.

8. Juvonen J, Gross EF. Extending the school grounds?--bullying experiences in cyberspace. J Sch Health 2008;78:496-505.

9. Staksrud E, Livingstone S. Children and online risk. Information, Communication \& Society 2009;12:364-87.

10. Ybarra ML, Mitchell KJ. Online aggressor/targets, aggressors, and targets: a comparison of associated youth characteristics. J Child Psychol Psychiatry 2004;45:1308-16.

11. Zhou Z, Tang H, Tian $\mathrm{Y}$, et al. Cyberbullying and its risk factors among chinese high school students. Sch Psychol Int 2013;34:630-47.

12. David-Ferdon C, Hertz MF. Electronic media, violence, and adolescents: an emerging public health problem. J Adolesc Health 2007:41:S1-S5.

13. Salmivalli C, Sainio M, Hodges EVE, et al. Antecedents, and consequences among elementary and middle school students. J Clin Child Adolesc Psychol 2013;42:442-53.

14. Staksrud E, Ólafssonb K, Livingstone S. Does the use of social networking sites increase children?s risk of harm? Comput Human Behav 2013;29:40-50.

15. Chang FC, Lee $\mathrm{CM}$, Chiu $\mathrm{CH}$, et al. Relationships among cyberbullying, school bullying, and mental health in taiwanese adolescents. J Sch Health 2013;83:454-62.

16. Wolak J, Finkelhor D, Mitchell KJ, et al. Online "predators" and their victims: myths, realities, and implications for prevention and treatment. Am Psychol 2008;63:111-28.

17. Elgar FJ, Napoletano A, Saul G, et al. Cyberbullying victimization and mental health in adolescents and the moderating role of family dinners. JAMA Pediatr 2014;168:1015-22.

18. Selkie EM, Fales JL, Moreno MA. Cyberbullying prevalence among US middle and high school-aged adolescents: a systematic review and quality assessment. J Adolesc Health 2016;58:125-33.

19. Korchmaros JD, Mitchell KJ, Ybarra ML. Technology-based interpersonal victimization: predictors of patterns of victimization over time. J Interpers Violence 2014;29:1297-317.

20. Brandtzaeg PB, Staksrud E, Hagen I, et al. Norwegian children's experiences of cyberbullying when using different technological platforms. J Child Media 2009;3:349-65.

21. Wolak J, Mitchell KJ, Finkelhor D. Does online harassment constitute bullying? an exploration of online harassment by known peers and online-only contacts. J Adolesc Health 2007;41:S51-S58

22. Ybarra ML, Espelage DL, Mitchell KJ. The co-occurrence of internet harassment and unwanted sexual solicitation victimization and perpetration: associations with psychosocial indicators. J Adolesc Health 2007;41:S31-S41.

23. Mitchell KJ, Wolak J, Finkelhor D. Are blogs putting youth at risk for online sexual solicitation or harassment? Child Abuse Negl 2008;32:277-94.

24. Wolak J, Finkelhor D, Mitchell K. Internet-initiated sex crimes against minors: implications for prevention based on findings from a national study. J Adolesc Health 2004;35:424.e11-424.e20.

25. Mitchell KJ, Finkelhor D, Wolak J. The internet and family and acquaintance sexual abuse. Child Maltreat 2005;10:49-60.

26. Chang C. Internet Safety survey: who will protect the Children ? Berkeley Technology Law Journal 2010;25:501-27.

27. Sourander A, Brunstein Klomek A, Ikonen M, et al. Psychosocial risk factors associated with cyberbullying among adolescents: a population-based study. Arch Gen Psychiatry 2010:67:720-8.

28. Menesini E, Nocentini A, Palladino BE, et al. Cyberbullying definition among adolescents: a comparison across six European countries. Cyberpsychol Behav Soc Netw 2012;15:455-63.

29. Hinduja S, Patchin JW. Offline consequences of online victimization: school violence and delinquency. Journal of School Violence 2007;6:89-112

30. Mishna F. Bullying: A guide to research, intervention and prevention. Oxford University Press: Oxford, 2012.

31. Williams KR, Guerra NG. Prevalence and predictors of internet bullying. J Adolesc Health 2007;41:S14-21.

32. Lindfors PL, Kaltiala-Heino R, Rimpelä AH. Cyberbullying among finnish adolescents--a population-based study. BMC Public Health 2012;12:1027-27.
33. Shapka JD, Law DM. Does one size fit all? ethnic differences in parenting behaviors and motivations for adolescent engagement in cyberbullying. J Youth Adolesc 2013;42:723-38.

34. Wang J, lannotti RJ, Nansel TR. School bullying among adolescents in the United States: physical, verbal, relational, and cyber. J Adolesc Health 2009;45:368-75.

35. Ortega R, Elipe P, Mora-Merchán JA, et al. The emotional impact on victims of traditional bullying and cyberbullying. $j$ Psychol 2009;217:197-204

36. Wade A, Beran T. Cyberbullying: the New Era of Bullying. Can J Sch Psychol 2011;26:44-61.

37. Floros GD, Siomos KE, Fisoun V, et al. Adolescent online cyberbullying in Greece: the impact of parental online security practices, bonding, and online impulsiveness. J Sch Health 2013:83:445-53.

38. Li Q. Cyberbullying in schools: A research of gender differences. Sch Psychol Int 2006;27:157-70.

39. Hinduja S, Patchin JW. Cyberbullying: An exploratory analysis of factors related to offending and victimization. Deviant Behav 2008;29:129-56.

40. Aricak T, Siyahhan S, Uzunhasanoglu A, et al. Cyberbullying among Turkish adolescents. Cyberpsychol Behav 2008;11:253-61.

41. Cohen LE, Felson M. Social change and crime rate trends: a routine activity approach. Am Sociol Rev 1979;44:588-608

42. Mesch GS. Parental mediation, online activities, and cyberbullying Cyberpsychol Behav 2009;12:387-93.

43. Mitchell KJ, Finkelhor D, Wolak J. Youth Internet users at risk for the most serious online sexual solicitations. Am J Prev Med 2007;32:532-7.

44. Ybarra ML, Mitchell KJ, Finkelhor D, et al. Internet prevention messages: targeting the right online behaviors. Arch Pediatr Adolesc Med 2007;161:138-45

45. Ybarra ML, Diener-West M, Leaf PJ. Examining the overlap in internet harassment and school bullying: implications for school intervention. $J$ Adolesc Health 2007;41:S42-S50.

46. Modecki KL, Barber BL, Vernon L, et al. Mapping developmental precursors of cyber-aggression: trajectories of risk predict perpetration and victimization. $J$ Youth Adolesc 2013;42:651-61.

47. Mitchell KJ, Ybarra M, Finkelhor D. The relative importance of online victimization in understanding depression, delinquency, and substance use. Child Maltreat 2007:12:314-24.

48. Valkenburg PM, Peter J. Online communication among adolescents: an integrated model of its attraction, opportunities, and risks. $J$ Adolesc Health 2011;48:121-7.

49. Wolak J, Finkelhor D, Mitchell K. Is talking online to unknown people always risky? distinguishing online interaction styles in a national sample of youth internet users. Cyberpsychol Behav 2008;11:340-3.

50. Digi Telecommunications. Safety Net: Growing Awareness among Malaysian schoolchildren on Staying Safe Online. A National Survey Report 2013. Shah Alam, Selangor, 2013.

51. Digi Telecommunications. Safety Net: Capacity Building Among Malaysian Schoolchildren on staying safe online. A National Survey Report 2014. Shah Alam, Selangor, 2014.

52. Digi Telecommunications. Growing digital resilience among Malaysian school children on staying safe online. The National Survey Report 2015. Shah Alam, Selangor, 2015.

53. Moreno MA. Social networking sites and adolescents. Pediatr Ann 2010;39:565-8

54. Tsitsika AK, Tzavela EC, Janikian M, et al. Online social networking in adolescence: patterns of use in six European countries and links with psychosocial functioning. J Adolesc Health 2014;55:141-7.

55. Messias E, Kindrick K, Castro J. School bullying, cyberbullying, or both: correlates of teen suicidality in the 2011 CDC youth risk behavior survey. Compr Psychiatry 2014;55:1063-8.

56. Marret MJ, Choo WY. Use of ICT by minors: key project findings. Kuala Lumpur: University of Malaya, 2014.

57. Shin W, Ismail N. Exploring the role of parents and peers in young adolescents' risk taking on social networking sites. Cyberpsychol Behav Soc Netw 2014;17:578-83.

58. Dunne MP, Zolotor AJ, Runyan DK, et al. ISPCAN child abuse screening tools retrospective version (ICAST-R): Delphi study and field testing in seven countries. Child Abuse Negl 2009;33:815-25.

59. Parker G, Roussos J, Hadzi-Pavlovic D, et al. The development of a refined measure of dysfunctional parenting and assessment of its relevance in patients with affective disorders. Psychol Med 1997;27:1193-203

60. Lenhart A. Teens, Social media and technology overview. Washington DC: Pew Research Center, 20152015

61. Livingstone S, Haddon L, Gorzig A, et al; Risks and safety on the internet: the perspective of european children: full findings and policy 
implications from the EU Kids Online survey of 9-16 year olds and their parents in 25 countries. London: EU Kids Online Network, 2011.

62. Mascheroni G, Olafsson K. Net children go mobile: Risks and opportunities. Milan: Educatt, 2014

63. Mitchell KJ, Jones LM, Finkelhor D, et al. Understanding the decline in unwanted online sexual solicitations for U.S. youth 2000-2010: findings from three youth internet safety surveys. Child Abuse Negl 2013;37:1225-36.

64. Madden M, Lenhart A, Cortesi S, et al. 2013. Teens, Social Media, and Privacy. Washington DC: Pew Research Center.

65. Peter J, Valkenburg PM, Schouten AP. Characteristics and motives of adolescents talking with strangers on the internet. Cyberpsychol Behav 2006;9:526-30.

66. Liu C, Ang RP, Lwin MO. Cognitive, personality, and social factors associated with adolescents' online personal information disclosure. J Adolesc 2013;36:629-38.

67. Price M, Dalgliesh J. Cyberbullying: experiences, impacts and coping strategies as described by Australian young people. Youth Studies Australia 2010;29:51-9.
68. Mitchell KJ, Finkelhor D, Wolak J, et al. Youth Internet victimization in a broader victimization context. J Adolesc Health 2011; 48:128-34.

69. Feng JY, Chang YT, Chang HY, et al. Prevalence of different forms of child maltreatment among Taiwanese adolescents: a populationbased study. Child Abuse Neg/ 2015;42:10-19.

70. Choo WY, Dunne MP, Marret MJ, et al. Victimization experiences of adolescents in Malaysia. J Adolesc Health 2011; 49:627-34.

71. Marret MJ, Choo WY. Victimization after meeting with online acquaintances: a cross-sectional survey of adolescents in Malaysia. $J$ Interpers Violence 2016

72. Liau AK, Khoo A, Ang PH. Factors influencing adolescents engagement in risky internet behavior. Cyberpsychol Behav 2005;8:513-20.

73. Badaly D, Kelly BM, Schwartz D, et al. Longitudinal associations of electronic aggression and victimization with social standing during adolescence. J Youth Adolesc 2013;42:891-904.

74. Schneider SK, O'Donnell L, Stueve A, et al. Cyberbullying, school bullying, and psychological distress: a regional census of high schoo students. Am J Public Health 2012;102:171-7. 